\title{
Faux Pas Test in schizophrenic patients
}

\author{
Teste de Faux Pas em pacientes com esquizofrenia \\ Juliana Negrão', Henrique Teruo Akiba², Vivian Renne Gerber Lederman', Álvaro Machado Dias²
}

\section{Keywords}

Schizophrenia, social cognition, Faux Pas Recognition Test.

\section{Palavras-chave}

Esquizofrenia, cognição

social, Teste de

Reconhecimento de

Faux Pas.

\section{ABSTRACT}

Objective: The aim of this study is to validate the adult version of "Faux Pas Recognition Test" created by Stone and colleagues (1998) as a reliable instrument assess and discriminate social cognition among schizophrenia patients and healthy controls. Methods: This is a cross-sectional study with a total of 196 participants (mean age $=26.45 ; \mathrm{Cl}(95 \%)$ [25.10; 27.83]) 51\% male. From those, 44 (22.4\%) patients with schizophrenia and 152 (77.6\%) healthy controls. The participants answered a short version of the Faux Pas Recognition Test, composed by 10 stories. Results: Significant differences were found between both groups regarding their scores on Faux Pas Recognition Test $(p=0.003)$. Patients with schizophrenia had lower score, compared to healthy controls. Story 14 was the best to distinguish both groups, and Story 16, the worst. Among the questions of Faux Pas stories, the one related to intuition presented the most significant difference between the groups $(p=0.001)$, followed by the one related to understanding ( $p=0.003)$. Conclusion: The Brazilian version of the Faux Pas Recognition Test is a valid test to assess social cognition in schizophrenia and can be an important instrument to be used on the clinical practice.

\section{RESUMO}

Objetivo: O objetivo deste estudo é validar a versão brasileira da versão adulta do Teste de Reconhecimento de Faux pas criado por Stone e colaboradores (1998) como um instrumento confiável para avaliar e discriminar a cognição social entre pessoas com esquizofrenia e controles saudáveis. Métodos: Trata-se de um estudo transversal com um total de 196 participantes (idade média $=26,45$; IC (95\%) [25,10; 27,83]), sendo 51\% homens; destes, 44 $(22,4 \%)$ eram pessoas com esquizofrenia e 152 (77,6\%), controles saudáveis. Os participantes responderam a uma versão reduzida do Teste de Reconhecimento de Faux Pas, contendo 10 histórias. Resultados: Foram encontradas diferenças significativas entre grupos no Teste de Reconhecimento de Faux Pas $(p=0,003)$. Pessoas com esquizofrenia obtiveram menor pontuação comparadas com o grupo controle. A história 14 foi a mais eficiente para distinguir os grupos, ao passo que a história 16 foi a pior. Quanto às questões das histórias Faux Pas, aquela referente à intuição foi a que apresentou maior diferença entre grupos $(p=0,001)$ seguida por compreensão $(p=0,003)$. Conclusão: A versão brasileira do Teste de Reconhecimento de Faux Pas é um instrumento válido para avaliar a cognição social em esquizofrenia e pode ser um instrumento importante a ser usado na prática clínica.

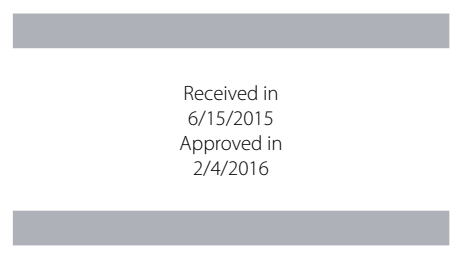

DOI: $10.1590 / 0047-2085000000098$
1 Presbyterian Mackenzie University, Developmental Disorders Program. 2 University of São Paulo, Institute of Psychology.

Address for correspondence: Juliana Gioia Negrão Universidade Presbiteriana Mackenzie. Rua Piauí, 181, Higienópolis 01241-001 - São Paulo, SP, Brazil. E-mail: juliana@negrao.com 


\section{INTRODUCTION}

Schizophrenic patients suffer from impaired social functioning ${ }^{1}$, such as compromised empathy and difficulties to initiate and maintain social interactions ${ }^{2}$. These difficulties are related to impaired social cognition, which expresses itself in traits such as abnormal perception and interpretation of others' intentions, ability known as Theory of Mind (ToM)1.

ToM is the ability of a person to attribute mental states, as beliefs, thoughts, intentions to oneself and others, understanding the distinction between agencies in both cases ${ }^{4}$. Among other impaired social cognition abilities, ToM deficits have been suggested as trait markers for schizophrenia, even in remission patients and has been found to be present in first degree relatives ${ }^{4-6}$.

The ability to prospect someone else's intentionality is linked to brain activity in different areas, among which the ventromedial prefrontal cortex (VMPC) and temporal-parietal junction (TPJ) play a prominent role ${ }^{7}$. Schizophrenia is a pervasive syndrome with symptoms that involve serious social cognitive deficits, which have been correlated with impaired brain activation in the two above-mentioned areas: VMPC and TPJ ${ }^{8}$.

ToM abilities can be evaluated using different tasks as stories or pictures reporting false beliefs, irony, faux pas or intentionality ${ }^{5,9}$. Studies with Mental State Attribution were initially done with autistic population ${ }^{6}$. Stone et al. ${ }^{10}$ developed the adult version of Faux Pas Recognition Test, which consists of stories describing Faux Pas situations, where characters interact and unintentionally say socially inadequate sentences. In order to understand the story, the subject must recognize that the character who said the sentence did not intend to offend the other character, and also assess the other interlocutor's feelings and describe how he must have felt in face of the socially awkward saying. After story presentation, a few questions are made in order to evaluate this process.

Previous studies showed significant difference between schizophrenic patients, their relatives and healthy controls in ToM index, evaluated by the Faux Pas Recognition Test. This index revealed a moderate to strong association with scores in the Scale for the Assessment of Negative Symptoms (SANS), showing correlation between the intensity of negative symptoms and worse performance in Faux Pas recognition in schizophrenic patients and even in their relatives. Mental State Attribution deficit could be influenced by genetics, and could be considered an endophenotype of this disease ${ }^{11,12}$.

The Faux Pas Recognition Test is a well-known instrument used to evaluate ToM in individuals with Autism Spectrum Disorders. Although, schizophrenic patients have similar ToM deficits, few instruments are able to target this function in this population.
The present study aims to validate a reduced, translated to Portuguese and cultural-adapted version of the Faux Pas Recognition Test as a reliable instrument to discriminate Mental State Attribution between Schizophrenia patients and matched healthy controls. The hypothesis is that schizophrenia patients should have lower scores compared to healthy controls. Our perspective is that this test can be of great clinical use.

\section{METHODS}

The ethical committee of the Federal University of São Paulo where the study was developed approved this study (09/54836-7). All participants agreed and signed the informed consent form, which was read and explained. Participants received an identification number to preserve their identity.

This cross-sectional study engaged 196 participants: 44 schizophrenia patients recruited from The Schizophrenia Program of the Federal University of São Paulo (PROESQ), a day-treatment program dedicated to schizophrenia and related disorders, and 152 healthy control volunteers.

The inclusion criteria for the clinical group (S) were: (i) Individuals with schizophrenia, diagnosed accordingly to the DSM-IV criteria and the Positive and Negative Syndrome Scale ${ }^{13}$; (ii) a minimum timespan of six months, in which the severe symptoms must be maintained. (iii) Age between 18 and 50 years. The inclusion criteria for the control group (C) were: (i) age between 18 and 35 years; (ii) score less than 7 points on Psychiatric Screening Questionnaire (SRQ-20) ${ }^{14}$, (iii) do not have either psychiatric or neurological disease history. The exclusion criteria were: (i) inability to diagnose schizophrenia, (ii) schizoaffective disorder; (iii) or inability to provide informed consent.

Ten stories $(2,3,5,8,11,14,16,17,18$, and 20) of Faux Pas Recognition Test ${ }^{11}$ were translated to Brazilian Portuguese and culturally adapted to Brazilian culture. A group composed by specialists in social cognition chose these stories and the final version was approved by judges with at least $\mathrm{PhD}$ degree. Five of the chosen stories were control conditions stories, without a faux pas $(3,5,8,17,20)$; and five were Faux Pas stories $(2,11,14,16$ and 18). Each subject listened and read the stories and answered eight standard questions afterwards. Six of the questions were directly related to the Faux Pas situation (1 and 2 - Faux Pas detection; 3 - understanding inappropriateness; 4 - intention; 5 - belief and 6 empathy) and the last two (questions 7 and 8), control questions, to assure the story comprehension, as described by Stone et al. $(1998)^{10}$. To ensure that the given answers were not affected by the lack of understanding of the story, only stories which had the last two answers correctly answered 
were accounted on the analysis. The reliability of the answers of each question was verified between groups. The data collection was made in a single individual session.

To analyze the results of this experiment the Mann-Whitney and Chi-square tests were employed for group comparison. Non-parametric statistics were used since normality approximations were rejected by Kolmogorov-Smirnov test. The comparison of the weight of each question, story and factor to discriminate (C) and (S) groups was performed using Logistic Regression. Cronbach's alpha coefficient was performed to evaluate internal consistency of the Faux Pas Recognition Test. The established significance level was $p<0.05$.

\section{RESULTS}

Groups were matched by gender $\left(X^{2}(1)=1.280, p=0.297\right)$, however, significant differences were found between age $(u=8,807, p<0.001)$ and socioeconomic status $(u=-6,107$, $p<0.001)$. While the $(S)$ group was composed by $59 \%$ males, mean age $39 \pm 11$ years, $52 \%$ of the subjects in A or B economic status by the ABIPEME Index (2012) the (C) group, had $48 \%$ males, mean age $22 \pm 4$ years, having $89 \%$ of the subjects in the A or B economic status.

The five control stories $(3,5,8,17$ and 20) were understood by both (S) and (C) groups with no significant differences ( $p=0.859$ ) (Table 1). On the other hand, story 16, one of the five Faux Pas stories, was not understood by the (S) group, as assessed by the control questions in this story.
The (S) group presented a significant difference with the (C) group ( $p=0.03$ ) in this story, so it was withdrawn from the analysis. The calculated Cronbach's alpha for the (S) group was 0.933 and 0.944 for the (C) group.

Among the four Faux Pas stories understood by both groups (stories 2, 11, 14 and 18), story 11 did not show significant values for identifying failure of Mental State Attribution $(p=0.351)$. Conversely, story 14 seemed to be the best for discrimination of ToM performance, and logistic regression infers that for each point achieved in this story, there is a $350 \%$ increase in the chance of the individual to be healthy. In story 2, each point increases chance in $82 \%$ of the individual to be healthy, while in story 18 , each point increase the chance by $43 \%$ (Table 1).

Table 2 represents the results of the Comprehension Questions of all the 10 stories. The (C) and (S) group showed significant differences responding only to Faux Pas questions $(p=0.003)$, while control questions were answered with no significant differences $(p=0.081)$.

Regarding the questions of the Faux Pas 4 stories $(2,11$, 14 , and 18), the two controls (questions 7 and 8) were understood by both groups, with no significant differences $(p=0.244)$, fitting their purpose. For the remaining questions (1 to 6), which relate directly to a Faux Pas situation, significant differences between the groups were observed and each question served its purpose. Question 4 (Intuition) was shown to be the one that most significantly discriminates both groups ( $p=0,001 ; O R=3.76)$, followed by question 3 (Understanding) $(p=0,003 ; O R=2.63)$ (Table 3).

Table 1. Performance on the Stories Comprehension in total Faux Pas Test

\begin{tabular}{|c|c|c|c|c|c|c|}
\hline \multirow[b]{2}{*}{ Faux Pas } & \multicolumn{2}{|c|}{ Group (Mean $\pm S D$ ) } & \multirow[b]{2}{*}{ P-value } & \multirow{2}{*}{$\begin{array}{l}\text { Odds Ratio } \\
\text { (OR) }\end{array}$} & \multicolumn{2}{|c|}{$95 \% \mathrm{Cl}$ for OR } \\
\hline & $\begin{array}{l}\text { Controls } \\
(n=152)\end{array}$ & $\begin{array}{l}\text { Schizophrenia } \\
\quad(\mathrm{n}=44)\end{array}$ & & & Lower & Upper \\
\hline $\mathrm{FPH} 2^{*}$ & $5.81 \pm 0.51$ & $4.09 \pm 2.23$ & 0.040 & 1.82 & 1.03 & 3.22 \\
\hline $\mathrm{FPH} 11^{*}$ & $5.62 \pm 1.22$ & $4.05 \pm 2.30$ & 0.351 & 1.17 & 0.84 & 1.62 \\
\hline $\mathrm{FPH} 14^{*}$ & $5.89 \pm 0.71$ & $3.11 \pm 2.64$ & $<0.001$ & 3.52 & 1.78 & 6.94 \\
\hline $\mathrm{FPH} 16^{*}$ & $5.63 \pm 1.22$ & $2.64 \pm 2.63$ & 0.001 & 2.38 & 1.44 & 3.92 \\
\hline $\mathrm{FPH} 18^{*}$ & $5.41 \pm 1.63$ & $3.73 \pm 2.42$ & 0.016 & 1.43 & 1.07 & 1.91 \\
\hline FPH CONTROL & $9.51 \pm 1.10$ & $8.14 \pm 2.81$ & 0.859 & 1.03 & 0.73 & 1.45 \\
\hline
\end{tabular}

* Items 1 to 6 of each story are included.

** FPH CONTROL is the sum of FPH3, FPH5, FPH8, FPH17, FPH20.

Table 2. Performance on the Comprehension Questions in total Faux Pas Test

\begin{tabular}{|c|c|c|c|c|c|c|}
\hline & \multicolumn{2}{|c|}{ Group (Mean $\pm S D$ ) } & \multirow[b]{2}{*}{ P-value* } & \multirow{2}{*}{$\begin{array}{l}\text { Odds Ratio } \\
\text { (OR) }\end{array}$} & \multicolumn{2}{|c|}{$95 \% \mathrm{Cl}$ for OR } \\
\hline & $\begin{array}{l}\text { Controls } \\
(n=152)\end{array}$ & $\begin{array}{l}\text { Schizophrenia } \\
\quad(n=44)\end{array}$ & & & Lower & Upper \\
\hline Faux Pas Question & $32.24 \pm 3.24$ & $23.11 \pm 8.90$ & 0.003 & 1.21 & 1.07 & 1.36 \\
\hline Control Question & $17.75 \pm 0.57$ & $16.18 \pm 2.58$ & 0.081 & 1.88 & 0.92 & 3.81 \\
\hline Total & $49.99 \pm 3.36$ & $39.30 \pm 10.46$ & 0.003 & 1.2 & 1.06 & 1.35 \\
\hline
\end{tabular}

* $p$-value from Logistic Regression controlling by age and social economic status. 
Table 3. Questions Performance on the 5 stories of the Faux Pas Test

\begin{tabular}{|c|c|c|c|c|c|c|}
\hline \multirow{3}{*}{ Faux Pas } & \multicolumn{2}{|c|}{ Group (Mean $\pm S D$ ) } & \multirow{3}{*}{ P-value } & \multirow{3}{*}{$\begin{array}{l}\text { Odds Ratio } \\
\text { (OR) }\end{array}$} & \multicolumn{2}{|c|}{$95 \% \mathrm{Cl}$ for OR } \\
\hline & Controls & Schizophrenia & & & \multirow{2}{*}{ Lower } & \multirow{2}{*}{ Upper } \\
\hline & $(n=152)$ & $(n=44)$ & & & & \\
\hline Detection & $7.72 \pm 0.86$ & $5.77 \pm 2.59$ & 0.006 & 1.98 & 1.21 & 3.23 \\
\hline Understanding & $3.81 \pm 0.57$ & $2.23 \pm 1.55$ & 0.003 & 2.63 & 1.38 & 5.02 \\
\hline Intuition & $3.74 \pm 0.59$ & $1.98 \pm 1.55$ & 0.001 & 3.76 & 1.75 & 8.07 \\
\hline Belief & $3.77 \pm 0.55$ & $2.64 \pm 1.46$ & 0.010 & 2.69 & 1.26 & 5.74 \\
\hline Empathy & $3.69 \pm 0.60$ & $2.36 \pm 1.42$ & 0.006 & 2.71 & 1.32 & 5.54 \\
\hline Story Comprehension & $7.89 \pm 0.33$ & $7.36 \pm 1.20$ & 0.244 & 1.76 & 0.68 & 4.57 \\
\hline
\end{tabular}

Stories included 1, 5, 6, 9

p-value Logistic Regression controlling by age and social economic status.

Story Comprehension is the sum of FPH1C1, FPH1C2, FPH5C1, FPH5C2, FPH6C1, FPH6C2, FPH9C!, FPH9C2.

\section{DISCUSSION}

Studies about mental state attributions in patients with schizophrenia point to the existence of a failure in agency attribution of mental states and behaviors, which have deep nosological connection to other symptoms of the syndrome. From the perspective of the cognitive dimension, affected subjects tend to have impairments in working memory, visual memory, verbal memory, verbal learning and visual stimuli, processing speed, executive functions and social cognition ${ }^{15,16}$. Other studies have shown the association of these deficits with gray matter reduction in the anterior cingulate cortex, dorsolateral prefrontal cortex, superior temporal gyrus and Insular; and less activation of the angular gyrus, inferior parietal lobe, inferior frontal gyrus and left middle temporal gyrus; thalamus, hippocampus and striatum may and intraparietal sulcus may be affected. The cortico-striato-thalamic circuitry may be strongly related to cognitive deficits in schizophrenia ${ }^{17}$.

Several studies have shown how difficult it is for individuals suffering with acute schizophrenic manifestations to properly deal with other people's intentions and actions. The Faux Pas Recognition Test is well established as an instrument that measures such qualifications through the recognition of gaffes, proved to be consolidated in the ASD (Autistic Syndrome Disorder) field ${ }^{18}$, differentiating them from healthy individual. However, little literature is found about its use in the assessment of schizophrenic patients, and there are no studies using it as a validated instrument in Brazil ${ }^{19,20}$.

The selected control stories served their purpose and were recognized by both groups. Faux Pas stories also served their purpose, allowing the discrimination between groups, except for story 16, which was removed to avoid interpretation biases; as both groups exhibited difficulties in comprehending it. Within the Faux Pas stories, all questions have shown relevance in identifying flaws in assigning mental status, being all equally important. Even with an understanding of the stories, the schizophrenic group failed to accomplish the Faux Pas. Similar results were found by other researchers ${ }^{21,22}$.

Failure to detect the social inadequacy of a sentence and understand the character's feelings in a story involving social interaction, may suggest how these individuals fail to understand social situations of their daily life ${ }^{23}$. Hasson-Ohayon et al. ${ }^{24}$ showed that individuals with schizophrenia have poor performance on metacognition and social cognition tasks impacting the social quality of their lives.

Another important characteristic of schizophrenic individuals is that they have difficulty distinguishing subjectivity and objectivity, as shown by the results of Faux Pas Recognition Test applied in them. Therefore, their misfit in relation to the environment increased the likelihood of a poor response to the applied task, because of their altered information processing ${ }^{25}$. In a meta-analysis conducted by Bora et al. ${ }^{5}$ found that cognitive deficits have intimate relation with ToM on patients with schizophrenia. These impairments remain even after symptom remission, suggesting that this cognitive disorder is a central trait in schizophrenia, associated with the way the individual relates socially, regardless of the environment ${ }^{26}$.

This study aimed to elucidate how a reduced version translated into Portuguese and culturally adapted Faux Past Test $^{10}$ is able to point out disparities in allocation of mental status between a group of schizophrenics and control group. In support of the hypothesis, it was observed that patients with schizophrenia have a major deficit of allocation mental status, compared to healthy controls, suggesting that the Faux Pas Recognition Test is suitable for measuring this cognitive process.

This study have common limitations regarding cross-sectional studies, making it difficult to make causal inferences, the results may differ if another time-frame had been chosen and it also may be affected by the prevalence-incidence bias. Although statistics corrections in an effort to avoid any bias, another important limitation to this study is the difference between samples regarding size, age and economic status. 
Finally, we used a single instrument to assess social cognition, as, until the moment of data collection, there was no other validated instrument to assess social cognition available in Brazil.

\section{CONCLUSION}

The Brazilian version of the Faux Pas Recognition Test is a valid instrument to access individuals suffering with schizophrenia. It is one of the few instruments available for ToM assessment in Brazil. Further studies with a larger cohort should follow this work, as well as a longitudinal study.

\section{INDIVIDUAL CONTRIBUTIONS}

Juliana Negrão - Wrote the manuscript draft and conducted the statistical analysis.

Henrique Teruo Akiba - Translated and adapted the instrument, collected data, supervised the statistical analysis and critically reviewed the paper.

Vivian Renne Gerber Lederman - Assisted on the composition of the manuscript draft and critically reviewed the paper.

Álvaro Machado Dias - Led the team, created the study design and critically reviewed the paper.

\section{CONFLICTS OF INTEREST}

The authors declare no competing financial interests.

\section{REFERENCES}

1. Couture SM, Penn DL, Roberts, DL. The functional significance of social cognition in schizophrenia: a review. Schizophr Bull. 2006;32 Suppl 1:S44-63.

2. Green MF, Penn DL, Bentall R, Carpenter WT, Gaebel W, Gur RC, et al. Social cognition in schizophrenia: an NIMH workshop on definitions, assessment, and research opportunities. Schizophr Bull. 2008;34(6):1211-20

3. Green MF, Bearden CE, Cannon TD, Fiske AP, Hellemann GS, Horan WP, et al. Social cognition in schizophrenia, Part 1: performance across phase of illness. Schizophrenia Bulletin. 2012;38(4):854-64

4. Sprong M, Schothorst P, Vos E, Hox J, van Engeland H. Theory of mind in schizophrenia: meta-analysis. Br J Psychiatry. 2007;191:5-13.
5. Bora $E$, Yucel $M$, Pantelis C. Theory of mind impairment in schizophrenia: meta-analysis. Schizophr Res. 2009;109(1-3):1-9.

6. Janssen I, Krabbendam L, Jolles J, van OS J. Alterations in theory of mind in patients with schizophrenia and nonpsychotic relatives. Acta Psychiatr Scand. 2003;108(2):110-7.

7. Saxe R, Wexler A. Making sense of another mind: the role of the right temporo-parietal junction. Neuropsychologia. 2005;43(10):1391-9.

8. Saxe R, Kanwisher N. People thinking about thinking people. The role of the temporoparietal junction in "theory of mind". Neuroimage. 2003;19(4):1835-42.

9. Brüne M. "Theory of Mind" in Schizophrenia: a review of the literature. Schizophr Bull. 2005;31(1):21-42.

10. Stone VE, Baron-Cohen S, Knight RT. Frontal lobe contributions to theory of mind. J Cogn Neurosci. 1998:10(5):640-56.

11. Martino DJ, Bucay D, Butman JT, Allegri RF. Neuropsychological frontal impairments and negative symptoms in schizophrenia. Psychiatry Res. 152:121-8.

12. de Achával D, Costanzo EY, Villarreal M, Jáuregui 10, Chiodi A, Castro MN, et al. Emotion processing and theory of mind in schizophrenia patients and their unaffected first-degree relatives. Neuropsychologia. 2010;48(5):1209-15.

13. Chaves AC, Shirukawa I. Escala das síndromes negativa e positiva - PANSS e seu uso no Brasil. Rev Psiq Clin. 1998;25(6):337-43.

14. Berwick DM, Murphy JM, Goldman PA, Ware JE Jr, Barsky AJ, Weinstein MC. Performance of a five-item mental health screening test. Med Care. 1991;29(2):169-76.

15. Nuechterlein KH, Barch DM, Gold JM, Goldberg TE, Green MF, Heaton RK. Identification of separable cognitive factors in schizophrenia. Schizophr Res. 2004;72(1):29-39.

16. Figueira ML. 0 valor científico das observações clínicas de Kraepelin para a investigação das perturbações do pensamento e linguagem na esquizofrenia. Psilogos. 2005;2(1):3952.

17. Sui J, Pearlson GD, Du Y, Yu Q, Jones TR, Chen J, et al. In Search of Multimodal Neuroimaging Biomarkers of Cognitive Deficits in Schizophrenia. Biol Psychiatry. 2015;78(11):794-804.

18. Happé FGE. Communicative competence and theory of mind in autism: a test of relevance theory. Cognition. 1993:48:101-19.

19. Caletti E, Paoli RA, Fiorentini A, Cigliobianco M, Zugno E, Serati M, et al. Neuropsychology, social cognition and global functioning among bipolar, schizophrenic patients and healthy controls: preliminary data. Front Hum Neurosci. 2013;7:661.

20. Gil AC. Métodos e técnicas de pesquisa social. São Paulo: Atlas; 1999.

21. Corcoran R, Mercer G, Frith CD. Schizophrenia, symptomatology and social inference: investigating "theory of mind" in people with schizophrenia. Schizophr Res. 1995;17(1):5-13.

22. Varga E, Tényi T, Fekete $S$, Herold $R$. The evaluation of mentalization deficit by the faux pas test in schizophrenia. Neuropsychopharmacol Hung. 2008;10(2):75-80.

23. Doody GA, Götz M, Johnstone EC, Frith CD, Owens DG. Theory of mind and psychoses. Psychol Med. 1998;28(2):397-405

24. Hasson-Ohayon I, Avidan-Msika M, Mashiach-Eizenberg M, Kravetz S, Rozencwaig S, Shalev $\mathrm{H}$, et al. Metacognitive and social cognition approaches to understanding the impact of schizophrenia on social quality of life. Schizophr Res. 2015;161(2-3):386-91.

25. Marques JT. Défice cognitivo na esquizofrenia. Lisboa: Vale \& Vale Editores, 2003.

26. McGurk SR, Mueser KT, DeRosa TJ, Wolfe R. Work, recovery, and comorbidity in schizophrenia: a randomized controlled trial of cognitive remediation. Schizophr Bull. 2009:35(2):319-35 